\title{
Numerical Simulations of Typhoon Hagupit (2008) Using WRF
}

\author{
JIA SUN \\ The First Institute of Oceanography, Ministry of Natural Resources, and Laboratory for Regional Oceanography and \\ Numerical Modeling, Qingdao National Laboratory for Marine Science and Technology, Qingdao, China

\section{HAILUN HE} \\ State Key Laboratory of Satellite Ocean Environment Dynamics, Second Institute of Oceanography, Ministry of \\ Natural Resources, Hangzhou, China

\section{XIAOMIN Hu AND DiNGQI WANG} \\ The First Institute of Oceanography, Ministry of Natural Resources, and Laboratory for Regional Oceanography and \\ Numerical Modeling, Qingdao National Laboratory for Marine Science and Technology, Qingdao, China \\ CEn GaO AND JinBaO SONG \\ Ocean College, Zhejiang University, Zhoushan, China
}

(Manuscript received 3 September 2018, in final form 18 May 2019)

\begin{abstract}
We used a mesoscale atmospheric model to simulate Typhoon Hagupit (2008) in the South China Sea (SCS). First, we chose optimized parameterization schemes based on a series of sensitivity tests. The results suggested that a combination of the Kain-Fritsch cumulus scheme and the Goddard microphysics scheme was the best choice for reproducing both the track and intensity of Typhoon Hagupit. Next, the simulated rainfall was compared with microwave remote sensing products. This comparison validated the model results for both the magnitude of rainfall and the location of heavy rain relative to the typhoon's center. Furthermore, the potential vorticity and vertical wind speed displayed the asymmetric horizontal and tilted vertical structures of Typhoon Hagupit. Finally, we compared the simulation of air-sea turbulent fluxes with estimations from an in situ buoy. The time series of momentum fluxes were roughly consistent, while the model still overestimated heat fluxes, especially right before the typhoon's arrival at the buoy.
\end{abstract}

\section{Introduction}

Each year, severe natural disasters in the form of highintensity tropical cyclones (TCs), also referred to as typhoons, develop in the western North Pacific Ocean (WNP) and the South China Sea (SCS). On average, tens of typhoons are generated every year, and more than one-third of them make landfall, causing great loss of life and having negative impacts on the local economy (Chen and Ding 1979; Fogarty et al. 2006). As an extreme event, supertyphoon Haiyan (2013) took at least 6300 lives and caused approximately $\$ 2$ billion (U.S. dollars) in damage in the Philippines (Galvin 2014). The profound impacts of these systems underscore the crucial

Corresponding author: Hailun He, hehailun@sio.org.cn importance of accurate typhoon forecasting. Unfortunately, there is still much room for improvement in today's predictions.

TC track forecasting has made great progress in the last three decades (Emanuel et al. 2004). From 1990 to 2017, the 48-h forecast error in the eastern North Pacific basin improved from $266 \mathrm{~km}$ (mean of 1990-99) to $184 \mathrm{~km}(2000-09)$ to $105 \mathrm{~km}(2010-17)$ according to the National Hurricane Center's official TC forecast report (Cangialosi 2018). These errors are comparatively small considering that the average horizontal scale of a TC is approximately $10^{\circ}$ longitude/latitude.

Compared with track forecasting, TC intensity forecasting did not improve as much during the same period (Emanuel et al. 2004). The mean 48-h forecast errors of TC intensity in the eastern North Pacific basin were 8.5, 
8.0 and $6.7 \mathrm{~m} \mathrm{~s}^{-1}$ for the 1990-99, 2000-09, and 2010-17 periods, respectively (Cangialosi 2018). One of the difficulties has to do with boundary layer processes, since air-sea heat fluxes are important energy sources for TCs (Cione et al. 2013; Cione 2015). Larger transfer coefficients for heat and water vapor promote more heat absorption from the ocean, leading to greater TC intensity. Simultaneously, sea spray also supplies new heat pathways from ocean to TC, which are generated by the breaking of surface waves or from wind blowing on wave crests. Specifically, Emanuel (1986) deduced the steadystate TC intensity, where the exchange coefficients of airsea turbulent fluxes (momentum flux, sensible heat flux, and latent heat flux) were key parameters. Meanwhile, a number of numerical tests supported the dependences of TC evolutions on air-sea fluxes (Bao et al. 2002; Green and Zhang 2013; Li et al. 2016). Current evaluations of model performance are still restricted to a time series of best track data (Bao 2016). Thus, more physical sounding comparisons are necessary for further exploration of model mechanics. Presently, numerical air-sea fluxes are rarely compared with in situ observations.

Recently, we deployed a mooring-based buoy in the northern SCS, which successfully captured the passage of Typhoon Hagupit (2008; Xu et al. 2017; He et al. 2018). The air-sea fluxes were then computed using widely used bulk formulas, noting that the uncertainty among multiple bulk estimations is considerable. The question then arises as to whether model simulated airsea fluxes are consistent with the observation-based results. To achieve a convincing comparison to a fixedposition buoy, we first needed to minimize the simulation TC track error. Therefore, we sought the best performance of TC track forecasts from an array of sensitivity tests.

Sensitivity tests are motivated by the models' imperfect physical parameterization schemes, which at a minimum include a cumulus parameterization scheme (CPS), microphysics parameterization scheme (MPS), and the aforementioned surface layer and planetary boundary layer schemes (Skamarock et al. 2008; Bao 2016; Li et al. 2016, 2018). The CPS is used to parameterize the subgrid-scale effects of convective and/or shallow clouds, which represent vertical fluxes due to unresolved updrafts and downdrafts and the compensating motions outside clouds. In contrast, the MPS includes explicitly resolved water vapor, cloud, and precipitation processes. Otherwise, to be consistent with the buoy-based bulk estimation, we keep the boundary layer scheme (together with surface layer scheme) unchanged in the sensitivity tests. Here we pursue better simulation by sensitivity tests but not data assimilation (Wu et al. 2010; Kunii 2015; Lin et al. 2018; Honda et al.
2018), because the latter inhibits the internal dynamics of numerical model.

Hence, the present paper attempted to evaluate the performance of an atmospheric model in the simulation of air-sea fluxes by using sensitivity tests of CPSs and MPSs. This paper is organized as follows: section 2 contains a description of the data, section 3 delineates the model configuration, section 4 includes the numerical results, and section 5 presents the conclusions.

\section{Data description}

\section{a. Best track of Typhoon Hagupit (2008)}

We used the TC best track data from the Japan Meteorological Agency (JMA) to determine the track and intensity of Typhoon Hagupit, as shown in Fig. 1. The best track data provide 6-hourly typhoon center locations, 10-min averaged maximum wind speeds (MWS), and minimum sea level pressure (MSLP). Typhoon Hagupit formed over the $\mathrm{WNP}$ at $\left(16.1^{\circ} \mathrm{N}, 141.2^{\circ} \mathrm{E}\right)$, moved westward, and intensified to a tropical storm east of the Philippine Islands. At $48 \mathrm{~h}$ after formation, Typhoon Hagupit entered the SCS through the Luzon Strait (LS) with an intensity that had increased to typhoon strength, finally making landfall at Dianbai in China.

\section{b. Sea surface temperature data}

Sea surface temperature (SST) data were provided by the National Oceanic and Atmospheric Administration's (NOAA's) National Climatic Data Center [NCDC; now known as the National Centers for Environmental Information (NCEI)]. We used the Optimum Interpolation Sea Surface Temperature Analysis (version 2; Reynolds et al. 2007). The data had a daily interval and a $0.25^{\circ} \times 0.25^{\circ}$ spatial resolution.

\section{c. Precipitation data}

The precipitation data used in this study were from the NASA Tropical Rainfall Measuring Mission (TRMM), version 7 . We used the multisatellite $3 \mathrm{~B} 42$ product to study the typhoon-induced rainfall in the SCS. These data provide 3-hourly precipitation with $0.25^{\circ} \times 0.25^{\circ}$ spatial resolution (Huffman et al. 2007).

\section{d. In situ mooring data}

Our mooring was located in the northern SCS $\left(19.5^{\circ} \mathrm{N}\right.$, $\left.115.5^{\circ} \mathrm{E}\right)$. The location was on the left side but very close to the track of Typhoon Hagupit (Fig. 1). The meteorological measurements from the mooring allowed bulk estimations of air-sea flux from in situ observations (He et al. 2018). Specifically, the observed air-sea turbulent fluxes were estimated using four bulk formulas 


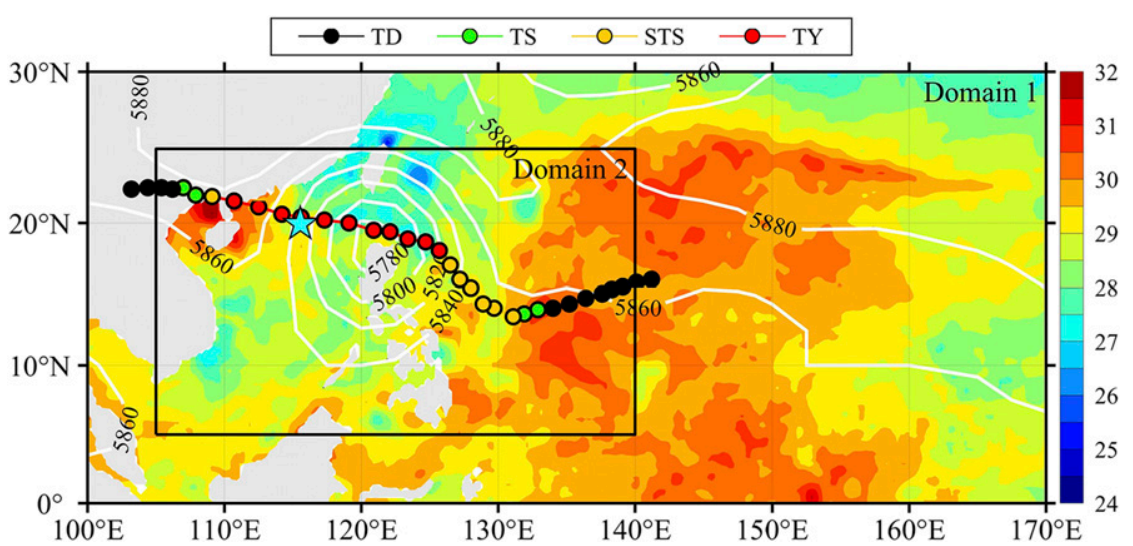

FIG. 1. Oceanic and atmospheric environments prior to Typhoon Hagupit (2008; at 0600 UTC $23 \mathrm{Sep})$. The colored dots and star denote the center of Typhoon Hagupit every $6 \mathrm{~h}$ and the location of the buoy, respectively. The shaded colors are SSTs $\left({ }^{\circ} \mathrm{C}\right)$, and the white contours denote 500-hPa geopotential heights (gpm). The model domains are also presented, where the horizontal resolutions are 30 and $10 \mathrm{~km}$ for the outer and inner domains, respectively.

(He et al. 2018). The first algorithm was from Large and Pond (1981, 1982, henceforth LP), the second one was COARE, developed by Fairall et al. (2003, henceforth COR), the third algorithm was COR, but with a surface wave-dependent roughness parameterization (Taylor and Yelland 2001, henceforth COR-WAVE), and the last algorithm added sea spray-related air-sea fluxes to the COARE parameterization (Andreas et al. 2008, henceforth COR-SPRAY).

\section{Model configuration}

We used the Weather Research and Forecasting (WRF) Model (version 3.5.1; Skamarock et al. 2008) for our numerical simulation. WRF is a fully compressible, nonhydrostatic, and terrain-following model. We set double-nested grids for the simulation of Typhoon Hagupit (Fig. 1). The large domain covered the area $0^{\circ}-30^{\circ} \mathrm{N}$, $100^{\circ}-170^{\circ} \mathrm{E}$ and employed $30-\mathrm{km}$ horizontal resolution; the inner domain covered $5^{\circ}-25^{\circ} \mathrm{N}, 105^{\circ}-140^{\circ} \mathrm{E}$ and used $10-\mathrm{km}$ horizontal resolution. The model had 30 vertical layers. It is noted that the grid setting here represents the current level of operational TC forecasting (Owens and Hewson 2018), and the $10 \mathrm{~km}$ is a suitable grid for cumulus parameterization from the theoretical consideration (Skamarock et al. 2008). Then, Hagupit was simulated from 1200 UTC 19 September to 0000 UTC 25 September, and the results were investigated after 24-h spinup.

The initial and boundary conditions were constructed with the National Centers for Environmental Prediction's (NCEP's) Final (FNL) Operational Model Global Tropospheric Analyses (NCEP 2000), for both atmospheric and surface information. NCEP FNL data is 6-hourly, and the spatial resolution is $1^{\circ} \times 1^{\circ}$. The initial condition displayed the background environmental flow (Fig. 1). The subtropical high located to the northeast of typhoon's trajectory induced Hagupit to move northwestward, following the 5860-gpm contour of geopotential height. Initial SSTs revealed the potential ocean heat release to the tropical cyclone. SSTs in the WNP were very high, showing the potential intense sensible heat flux release to the TC, which can aid intensification. SSTs were relatively cool near the LS, which restricted the ocean heat release to the typhoon. After passing through the LS, Hagupit again moved over warmer SSTs, which further helped it maintain typhoon intensity.

For the sensitivity tests, we considered a series of simulations with different CPSs and MPSs. Specifically, we conducted simulations with six different CPSs, including the Kain-Fritsch (KF; Kain 2004), Betts-MillerJanjić (BMJ; Janjić 1994), Grell-Devenyi (GD; Grell and Dévényi 2002), simplified Arakawa-Schubert (SAS; Pan and Wu 1995), Grell-3 (G3), and Tiedtke (Tie; Tiedtke 1989) schemes. Meanwhile, eight MPSs were employed, including the Kessler (Kessler 1969), Lin (Lin et al. 1983), WSM3 (Hong et al. 2004), WSM5 (Hong et al. 2004), Eta (Ferrier) (henceforth Eta; Rogers et al. 2001), WSM6 (Hong and Lim 2006), Goddard (Tao et al. 2011), and Thompson (Thompson et al. 2008) schemes.

Generally, these schemes are the main CPS and MPS parameterization options of WRF (Skamarock et al. 2008). For CPSs, these schemes are diverse in the sense of trigger function and closure assumption, where the former (trigger function) determines the cumulus presence, and the latter (closure assumption) quantifies the intensity of vertical motion (or latent 

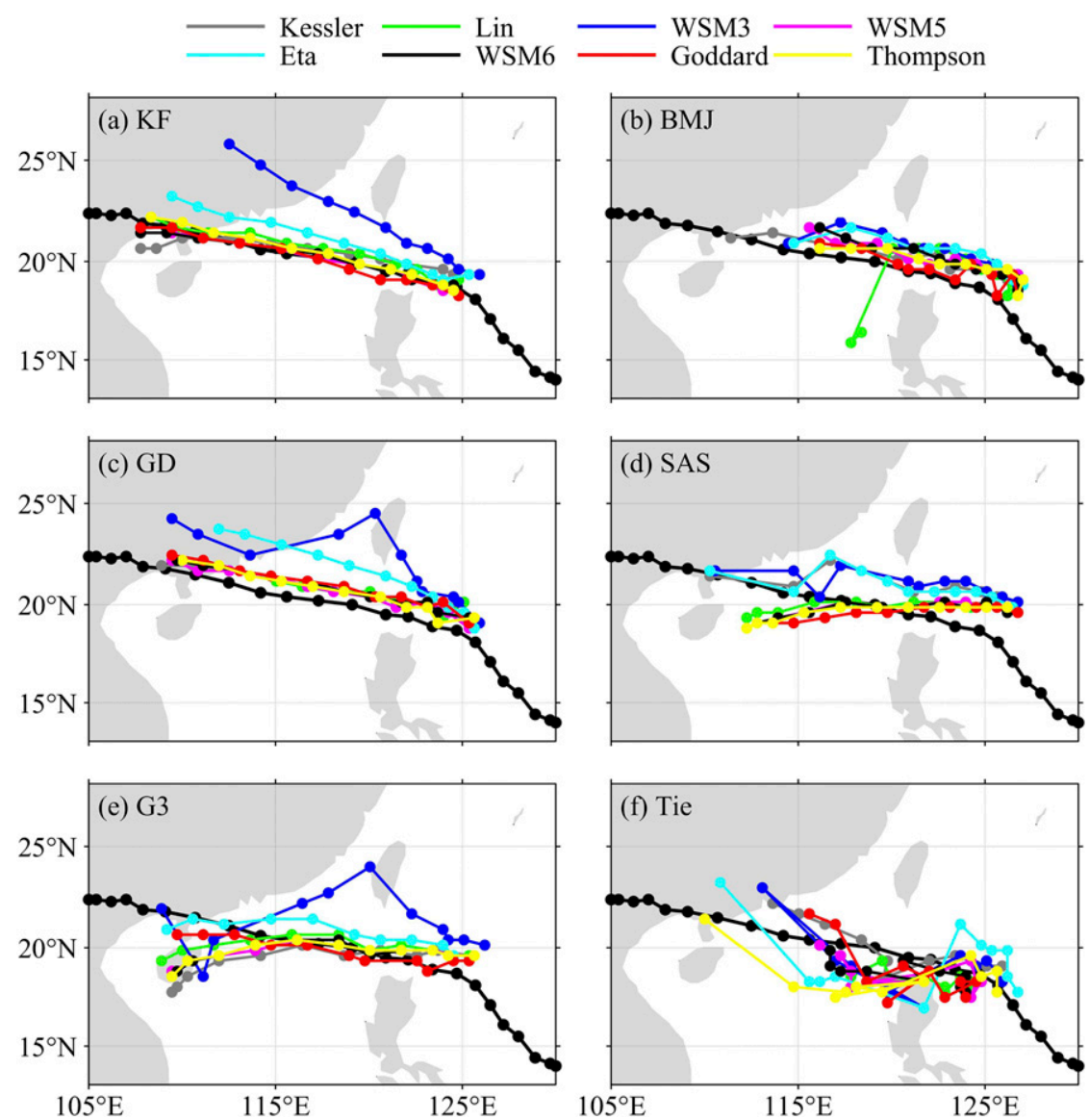

FIG. 2. Simulated tracks from the sensitivity experiments: CPS using the (a) KF, (b) BMJ, (c) GD, (d) SAS, (e) G3, and (f) Tie schemes. Black lines denote the JMA best tracks (6 h as the time interval).

heating; Stensrud 2009). MPSs describe the state of the primary microphysical species, which include water vapor, cloud droplets, rain droplets, cloud ice crystals, snow, rimed ice, graupel, and hail, and MPSs are different on the variable numbers, yes-or-no ice-phase processes, and interactions between species (Skamarock et al. 2008).

For the other physical processes, we selected surface layer and planetary boundary layer schemes in the forms of the MM5 similarity scheme (Jiménez et al. 2012) and Yonsei University scheme (Hong and Lim 2006), respectively. We also chose the Dudhia scheme (Dudhia 1989) and the RRTM (Mlawer et al. 1997) scheme for shortwave and longwave radiation parameterizations, respectively. It is noted that the selected surface layer scheme adopts the COARE formula for the exchange coefficients of momentum, heat, and moisture, which is consistent with buoy data analysis (He et al. 2018). Meanwhile, the Yonsei University scheme is a conjunctional boundary layer scheme for the MM5 similarity scheme (Chan and Chan 2016).

\section{Results}

\section{a. Sensitivity tests}

\section{1) TRACK AND INTENSITY}

Figure 2 shows the simulated TC tracks of the 48 sensitivity experiments. Here, we determined the TC center using MSLP. It is evident that the CPS plays a dominant role in track simulation, as seen in Fig. 2. The KF cumulus scheme replicated the TC track well in the SCS, while the tracks associated with the other CPSs deviated a great deal. Averaged track errors using the KF cumulus and 8 different MPSs were $60.3 \mathrm{~km}$ (Kessler), $39.0 \mathrm{~km}$ (Lin), $271.2 \mathrm{~km}$ (WSM3), $21.1 \mathrm{~km}$ (WSM5), $113.9 \mathrm{~km}$ (Eta), $21.1 \mathrm{~km}$ (WSM6), $24.9 \mathrm{~km}$ (Goddard), and $23.0 \mathrm{~km}$ (Thompson). Thus, the best track performance of the KF cumulus scheme had an average error of $21.1 \mathrm{~km}$, achieved by both the WSM5 and WSM6 microphysics schemes. It is also notable that the WSM3 and Eta microphysics schemes were not suitable for the present track simulation since their averaged track 

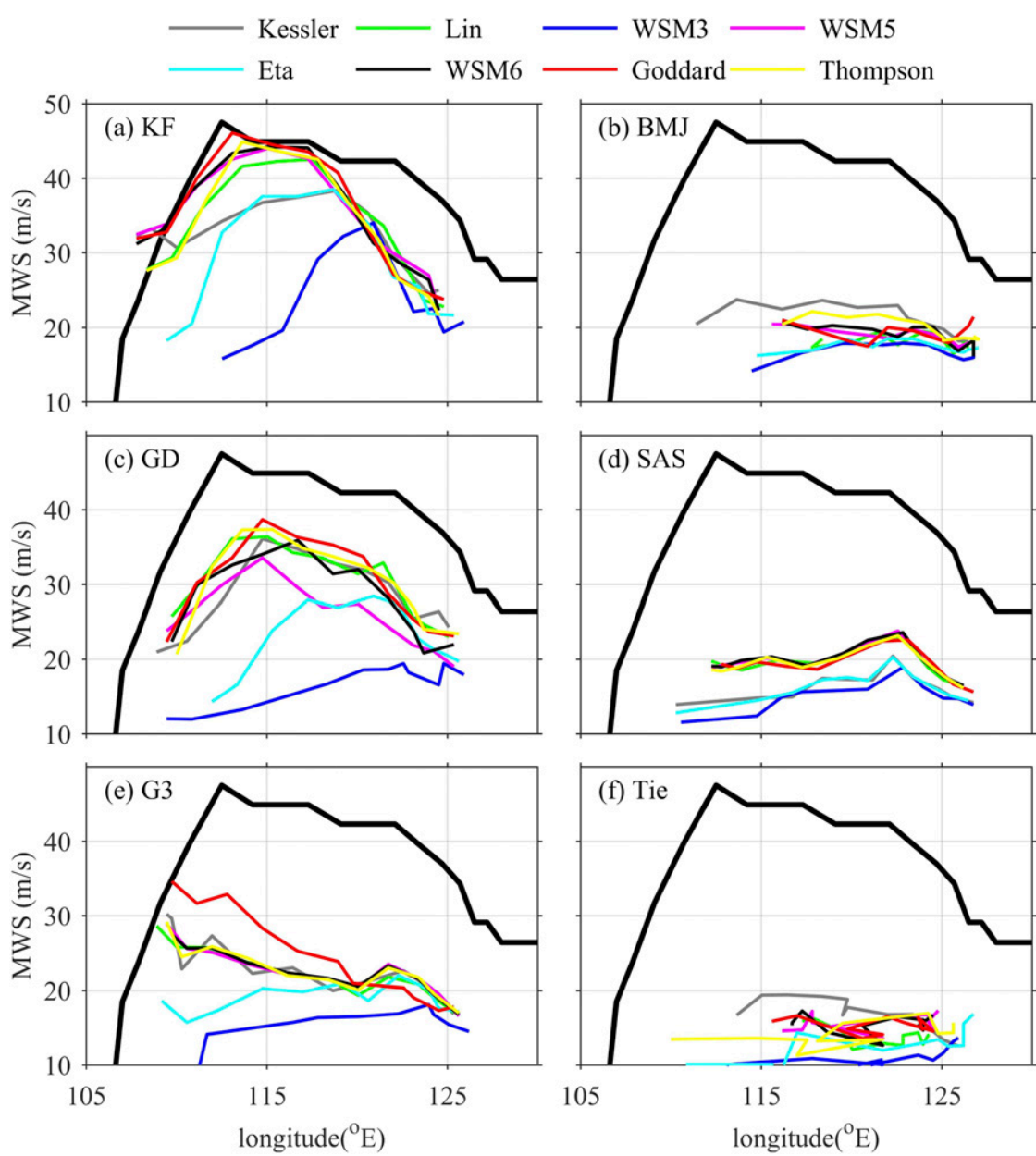

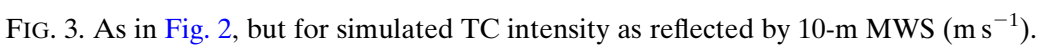

errors exceeded $100 \mathrm{~km}$. For the other CPSs, the track errors were far greater than those of the KF. Specifically, the BMJ scheme resulted in slow movement with no eventual landfall, the GD-simulated tracks were quite similar to those of the KF but farther north than the best track, the SAS scheme produced southwestward and tortuous westward-moving tracks, the G3 scheme simulated southward-moving TCs, and the Tie scheme resulted in unstable and deviant track simulations. These results show that KF-WSM5 and KF-WSM6 are the optimized combinations of CPS and MPS for TC track simulation of the study case, and KF-Goddard is a relatively good choice of track simulation.

The other aspect of TCs, typhoon intensity, also shows great dependence on CPS and MPS; the results are shown in Figs. 3 and 4. Fortunately, the KF again performed better than the other CPSs in the intensity simulation. Some KF-simulated MWSs closely approximated the best track data. In combination with the KF cumulus scheme, the WSM3 and Eta resulted in relatively poor intensity simulations compared with other MPSs. Excluding these 2 schemes, the mean simulated intensity errors of the 6 remaining experiments run with the KF cumulus scheme were $7.8 \mathrm{~m} \mathrm{~s}^{-1}$ (MWS) and $15.0 \mathrm{hPa}$ (MSLP). For typhoon intensity, the best MPS in combination with the KF was the Goddard, which yielded mean MWS and MSLP simulation errors of only $6 \mathrm{~m} \mathrm{~s}^{-1}$ and $11.3 \mathrm{hPa}$, respectively. In comparison, the other CPSs led to weaker intensities. The BMJ, SAS, G3, and Tie schemes failed to replicate the evolution of Typhoon Hagupit. The GD scheme produced a similar, though weaker, evolution than the KF (Figs. 3c and $4 \mathrm{c}$ ), with corresponding mean MWS and MSLP errors of $11.3 \mathrm{~m} \mathrm{~s}^{-1}$ and $21.5 \mathrm{hPa}$, respectively, when the anomalous WSM3 and Eta schemes were excluded. It is also noted that, at the beginning of simulations, TC intensities were always underestimated due to the initial condition given by NCEP FNL. The simulated TCs were then rapidly intensified after entering SCS.

The overall evaluation of the sensitivity tests is displayed in Fig. 5. The advantages of the KF scheme over 

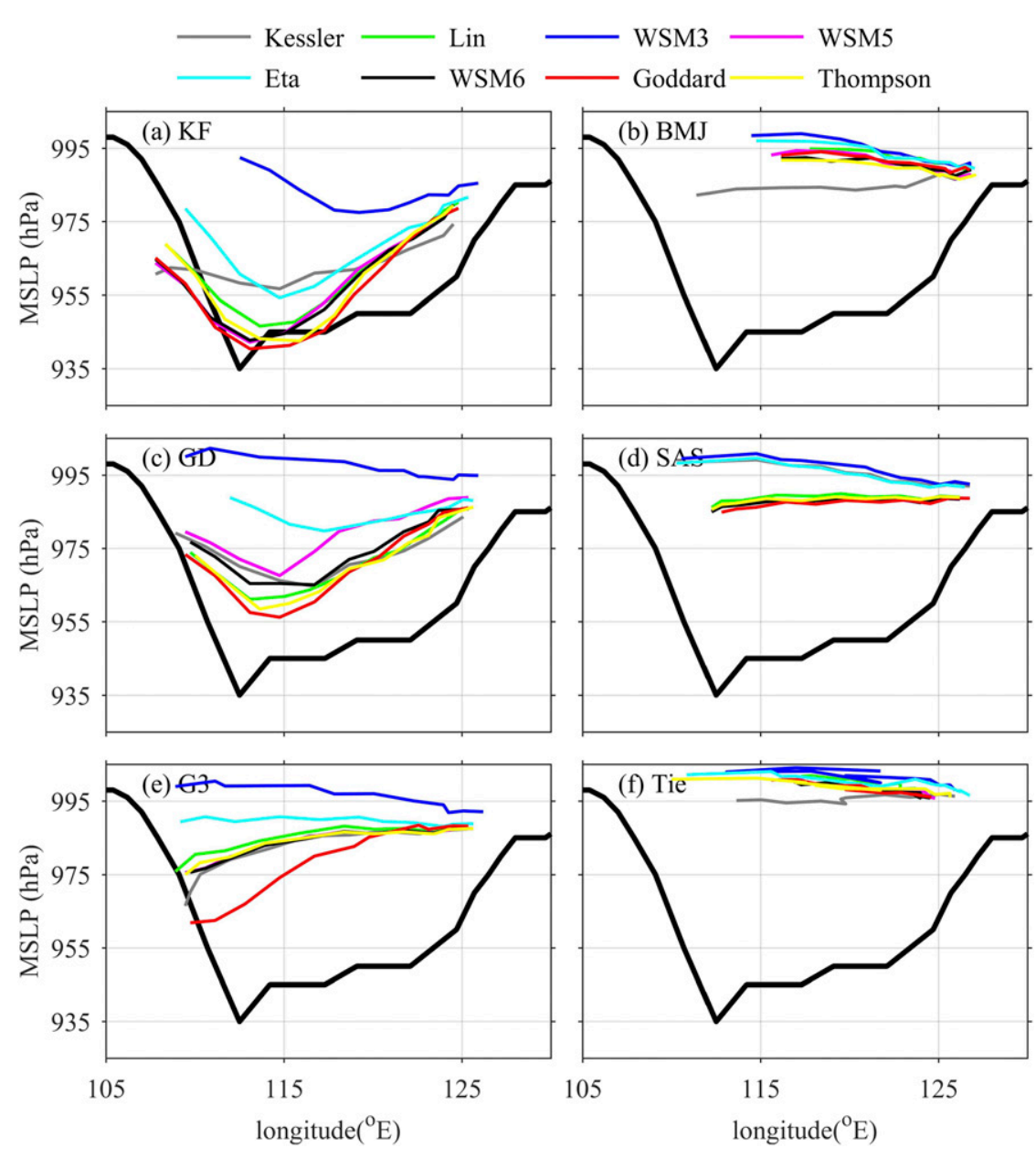

FIG. 4. As in Fig. 2, but for simulated TC intensity as reflected by MSLP (hPa).

the other CPSs are obvious for both TC track and intensity simulations. The performances of CPS and MPS schemes reflect the underlying physics in some extent. For instance, KF CPS calculates the tendencies of cloud, rain, ice and snow, and it includes both deep and shallow convections, while GD CPS only includes tendencies of cloud and ice, and it excludes shallow convection. The incomplete representation of cloud therefore impedes GD resolving more cumulus activity. Also, Goddard MPS shows advantage over Kessler. Goddard is a sophisticated scheme including ice, snow, and graupel processes, while the Kessler scheme is relatively simple as it only concerns the warm rain process.

\section{2) AIR-SEA FLUXES}

The sensitivity tests reveal that most experiments underestimate the TC intensities. Because latent heat flux is a main heat source for TC development, we investigate the air-sea turbulent heat fluxes (latent heat flux and sensible heat flux) for an explanation.
CPS-categorized ensemble mean latent heat fluxes show different magnitudes and patterns (Fig. 6). KF cumulus, whose TC tracks mostly resemble the best track, induces more than $300 \mathrm{~W} \mathrm{~m}^{-2}$ for latent heat flux along the TC track in SCS, and the maximum value attains $350 \mathrm{~W} \mathrm{~m}^{-2}$ (Fig. 6a). Meanwhile, the latent heat fluxes in central SCS (around $15^{\circ} \mathrm{N}$ ) and WNP are less than $150 \mathrm{~W} \mathrm{~m}^{-2}$. Although the pattern of GD latent heat flux is similar to that of KF, its magnitude is $100-150 \mathrm{~W} \mathrm{~m}^{-2}$ lower. We speculate that the lower latent heat flux (Fig. 6c) is responsible for the simulated weak intensity (Fig. 3c and 4c). For BMJ and SAS (Fig. 6b and 6d), the simulated latent heat fluxes are both weak in the SCS, especially at east of $115^{\circ} \mathrm{E}$. Nonetheless, the latent heat fluxes along the coast explain the intensification of the simulated TC prior to landfall (Figs. 3b,d and $4 \mathrm{~b}, \mathrm{~d})$. The similar pattern can be found in the G3 experiments (Fig. 6e). In Fig. 6f, the latent heat flux simulated by the Tie cumulus scheme was very weak, explaining its failure to simulate Typhoon Hagupit. 
(a)

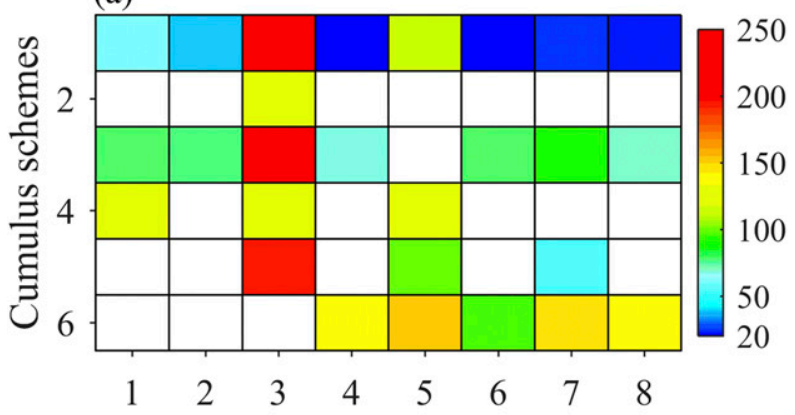

(b)

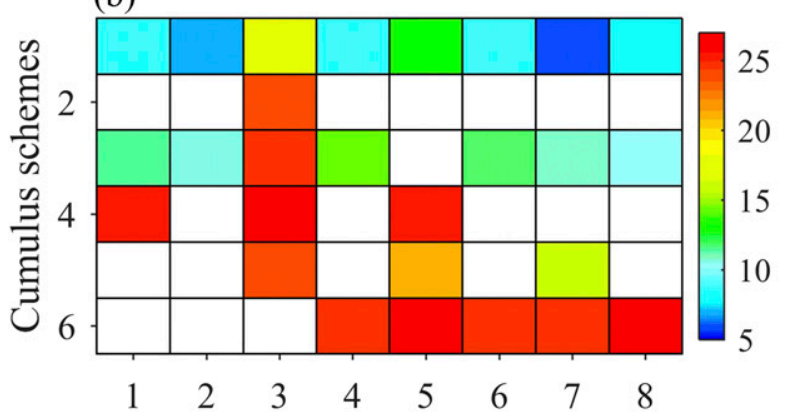

(c)

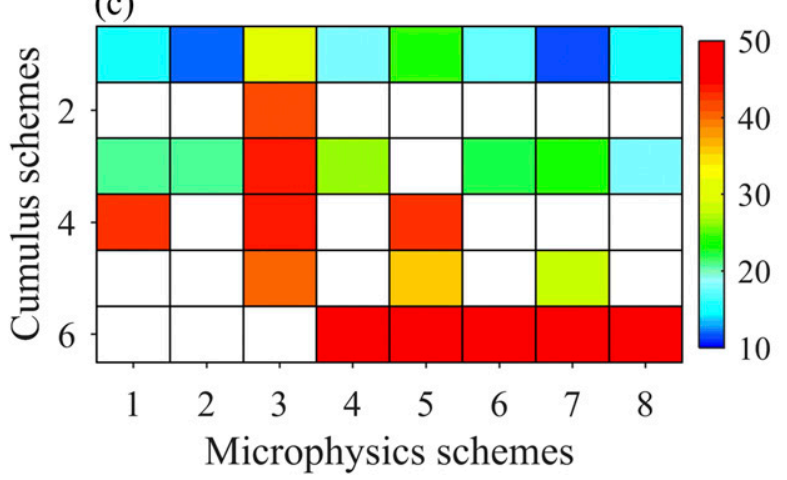

FIG. 5. Simulation errors of the sensitivity tests: (a) TC track (km) (b) 10-m MWS $\left(\mathrm{m} \mathrm{s}^{-1}\right.$ ), and (c) MSLP (hPa). Blank cells denote hindcast failures. Numbers $1-6$ of the cumulus schemes denote the KF, BMJ, GD, SAS, G3, and Tie schemes, respectively; and numbers $1-8$ of the microphysics schemes represent the Kessler, Lin, WSM3, WSM5, Eta, WSM6, Goddard, and Thompson schemes, respectively.

Similarly, for the sensible heat flux (Fig. 7), due to the good simulation of track, KF and GD give trackfollowing distributions. Compared with the latent heat flux, the sensible heat flux is relatively small, whereas the maximum value of $\mathrm{KF}$ is about $50 \mathrm{~W} \mathrm{~m}^{-2}$.

When we consider both latent heat flux and sensible heat flux, some points are achieved as follows. 1) The patterns are mostly determined by track performance, and both latent heat flux and sensible heat flux are relatively strong along the tracks. 2) Because latent heat flux is a main component of wind-induced heat exchange (WISHE) mechanism (Emanuel 1995, 1997), the phenomena in point 1 therefore emphasizes the positive feedback of the ocean to the TC, or the WISHE effect. 3) The surface layer and boundary layer schemes are kept the same, and the differences of CPS-categorized ensemble means of latent heat flux (also sensible heat flux) are devoted to the CPSs. In this case, KF produced relatively good performances of track and intensity. While for other CPSs, the errors of track and intensity would be further amplified due to insufficiently resolving the ocean-TC interactions.

\section{3) OUtgoing LONGWAVE RADIATION}

The outgoing longwave radiation (OLR) at the top of the atmosphere indicates TC convection and cloud coverage, and lower OLR represents more intensive TC convection. Model-simulated OLR structures of Typhoon Hagupit over the SCS are shown in Fig. 8. With the KF scheme, the simulated convection was enhanced east of $113^{\circ} \mathrm{E}$ (Fig. 8a), accompanied by rapid TC intensification and great strength. The low OLR values west of the Philippine Islands may be the result of widespread cloud coverage associated with the rapid intensification that was occurring when Hagupit entered the SCS. Analogous to the sensible heat flux, the GD-simulated OLR was similar to, but much weaker than, the value in the KF runs (Fig. 8), suggesting that convection in the GD experiments was weaker than that in the KF simulations. Convection in the SCS was depressed in experiments run with the BMJ scheme (Fig. 8b), explaining the low westward speeds and weak TC intensities. Both the SAS and Tie runs generated weaker convection (Figs. 8d and 8f) compared with the other CPSs. It is interesting to note that the OLR patterns in the G3 runs were quite similar to those in the KF and GD simulations. Replication of Typhoon Hagupit by the G3 cumulus scheme eventually failed, however.

\section{b. Selected simulations}

Overall, the KF cumulus scheme performed better in hindcasting Typhoon Hagupit, and the combination of the KF cumulus and Goddard microphysics schemes best reproduced both the track and intensity of Hagupit over the SCS. In the following section, we analyze simulation results with these two schemes in an attempt to understand the underlying physics of Typhoon Hagupit over the SCS.

\section{1) TRACK AND INTENSITY}

The simulated track and intensity of Typhoon Hagupit are shown in Fig. 9. The simulated track was almost identical to the JMA best track. The simulated intensity 

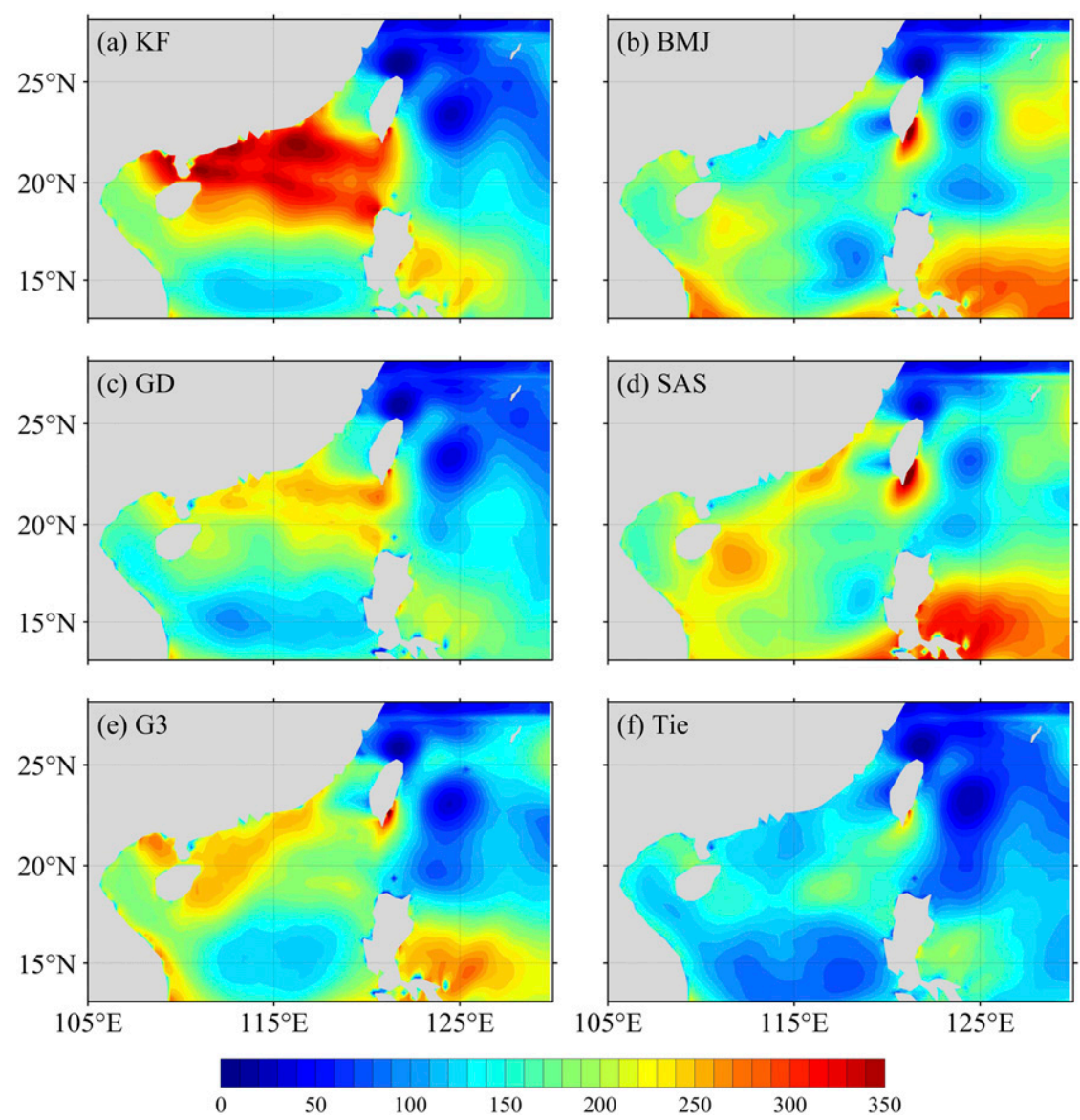

FIG. 6. CPS-categorized ensemble mean results of duration mean latent heat fluxes $\left(\mathrm{W} \mathrm{m}^{-2}\right)$ from the sensitivity experiments: CPS is the (a) KF, (b) BMJ, (c) GD, (d) SAS, (e) G3, and (f) Tie schemes, respectively.

agreed with the best track data after the entrance of Hagupit into the SCS west of $120^{\circ} \mathrm{E}$. The mean simulation errors of track and intensity (MWS and MSLP) from 1800 UTC 21 September to 0600 UTC 24 September 2008 were $24.9 \mathrm{~km}, 11.3 \mathrm{~m} \mathrm{~s}^{-1}$, and $6.0 \mathrm{hPa}$, respectively. It is notable that the simulated errors of TC track, MWS, and MSLP were only $18.4 \mathrm{~km}, 0.5 \mathrm{~m} \mathrm{~s}^{-1}$ and $3.2 \mathrm{hPa}$, respectively, when the TC arrived at the longitude of the buoy. Furthermore, Figs. 9d-i show the spatial distributions of $10-\mathrm{m}$ wind and SLP, where the strong winds located around high SLP gradient, and the comparisons of 50-kt $\left(1 \mathrm{kt} \approx 0.51 \mathrm{~m} \mathrm{~s}^{-1}\right)$ wind radius between best track and simulation were considerably good. Thus, this accurate replication of Typhoon Hagupit passing by the buoy can be used for detailed analysis.

\section{2) Precipitation}

Precipitation variations are correlated with changes in TC structure. Therefore, we validated our numerical rainfall with TRMM data, as shown in Fig. 10. On the one hand, the model precipitation had a spatial pattern similar to that of the precipitation derived from satellite data. Both simulation and satellite exhibited strong precipitation around the center of the typhoon, with both containing maxima in the left and front regions of the storm. On the other hand, differences between the model and the TRMM were still significant. For instance, model-simulated precipitation was more concentrated than rainfall derived from satellite data. Satellite-sensing rainfall covered an area with a radius of $\sim 400 \mathrm{~km}$, which was much larger than that produced by the model $(<200 \mathrm{~km})$. Maximum precipitation in the model was stronger (weaker) than observed values before (after) 0600 UTC 23 September. Maximum simulated precipitation in the 4 snapshots shown in Fig. 10 were 42.6, $41.5,39.3$ and $53.7 \mathrm{~mm} \mathrm{~h}^{-1}$, respectively. The corresponding values in the TRMM data were 35.2, 32.0, 48.4 and $49.6 \mathrm{~mm} \mathrm{~h}^{-1}$, respectively. The rainfall inconsistencies between observations and model illustrate the difficulty of simulating typhoon precipitation. 

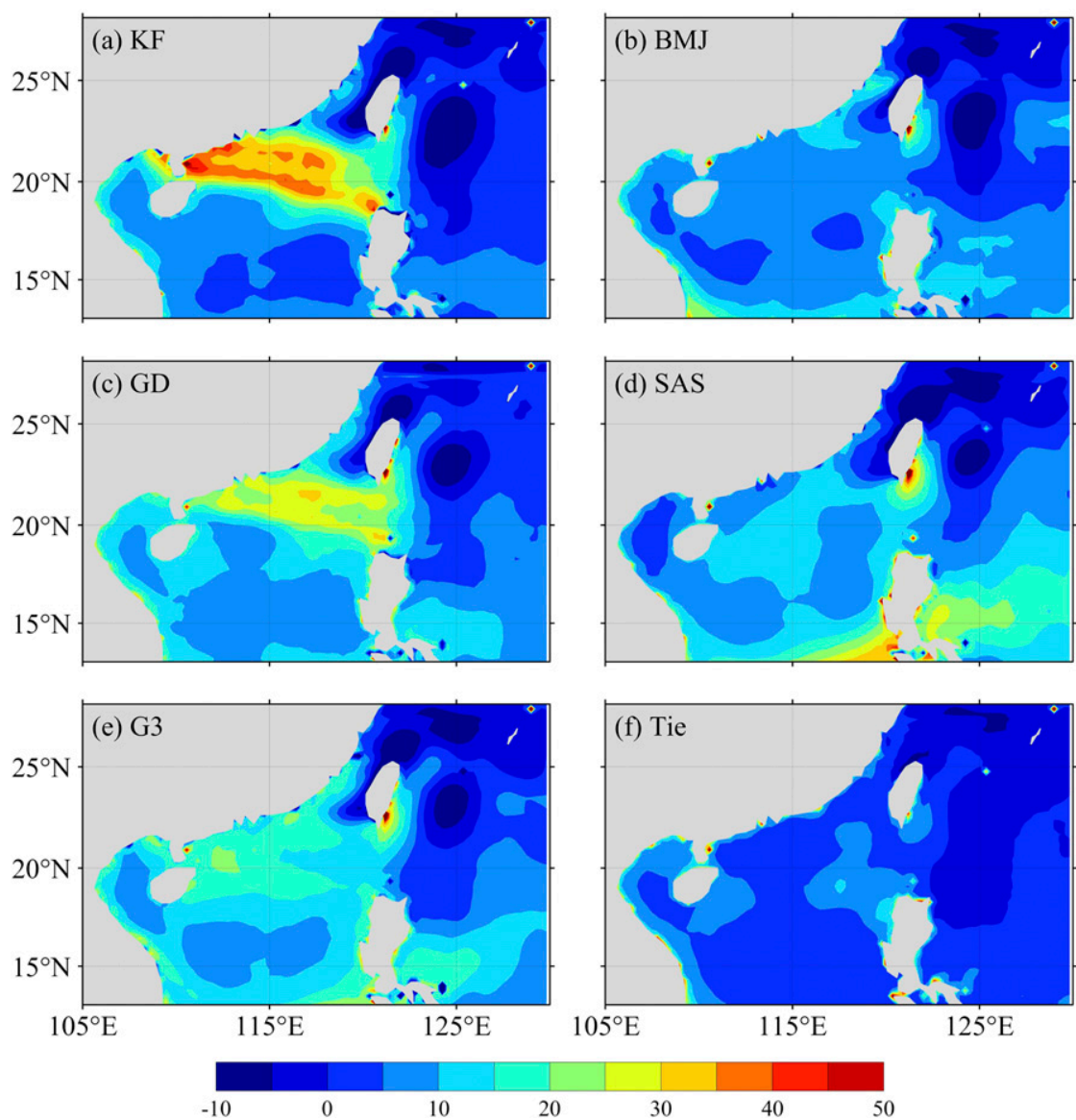

FIG. 7. As in Fig. 6, but for sensible heat fluxes $\left(\mathrm{W} \mathrm{m}^{-2}\right)$.

\section{3) Potential Vorticity}

The typhoon is considered to be a positive potential vorticity (PV) anomaly in the atmospheric flow environment, and its movements are closely linked to this positive PV tendency (henceforth PVT; Wu and Wang 2000; Wu and Emanuel 1993; Yun et al. 2012; Choi et al. 2013). To further explore the dynamics of Typhoon Hagupit, we calculated the PVT during its lifetime following the method of $\mathrm{Wu}$ and Wang (2000). For the investigation of Hagupit's vertical structure, the atmosphere was divided into 3 layers: the bottom layer, the middle layer, and the top layer, defined as $0-0.35$, $0.35-0.7$ and $0.7-1$ in eta levels of the WRF Model, respectively. The PVT structures of these layers are shown in Figs. 11a-r. As seen in figures, the PVT structures in the bottom and middle layers were distinct enough to reveal the tendency of TC movement, with a negative maximum at the current $\mathrm{TC}$ center and a positive maximum at its next position. Compared to the middle layer, the PVT in the bottom layer indicated the TC center more concisely, with extreme PVT values more concentrated toward the TC center. PVT of the top layer was much more complex and unable to reveal the TC translation tendency. These three vertical layers exhibited the more organized TC structure in lower layers and the unorganized structure in the top layer during Typhoon Hagupit.

The vertical variations of Typhoon Hagupit were also indicated by vertical wind speed (VWS). As shown Figs. 11s-x, Hagupit's radius of MWS (RMWS) expanded with increasing height. The RMWS was $20-40 \mathrm{~km}$ in the bottom layer, $40-50 \mathrm{~km}$ in the middle layer, and $>50 \mathrm{~km}$ in the top layer. Updrafts near the eyewall illustrated the tilted vertical structure of Typhoon Hagupit. In addition, it was also obvious that the VWSs were much stronger in the southern portion of this system than in its northern part, suggesting that Hagupit had an asymmetric horizontal structure. This is consistent with the spatial structure of its precipitation.

\section{4) AIR-SEA FluXes}

Focusing on our buoy located in the SCS, we examined the characteristics of Typhoon Hagupit west of $120^{\circ} \mathrm{E}$. While Hagupit was in the SCS, its intensity 

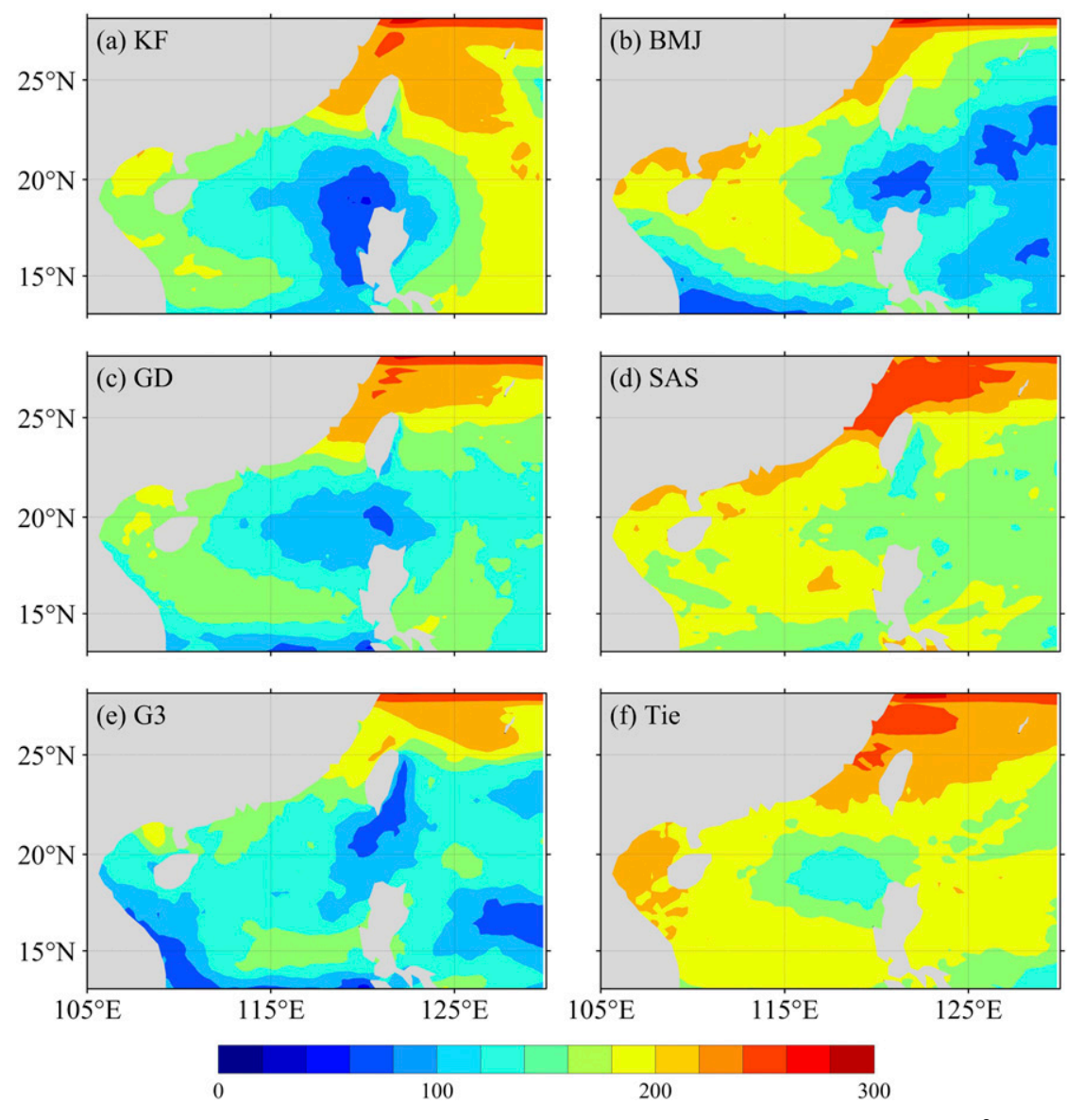

FIG. 8. As in Fig. 6, but for simulated OLR at the top of the atmosphere ( $\left.\mathrm{W} \mathrm{m}^{-2}\right)$.

increased until 1800 UTC September 23. An evolutionary timetable that was successfully captured by the WRF Model simulation (Fig. 9b). The averaged air-sea fluxes (sensible heat flux and latent heat flux) were defined as the area-averaged flux values within a radius of $150 \mathrm{~km}$ from the typhoon's center.

It is evident that the increases in air-sea fluxes kept pace with Hagupit's level of intensity. As shown in Fig. 12, the air-sea latent heat fluxes were $200-300 \mathrm{~W} \mathrm{~m}^{-2}$ prior to 0600 UTC 22 September, which led to the steady intensification of the simulated Hagupit. This process was also seen in the warm core development (Fig. 12a). The warm anomaly appeared through the entire atmosphere, with two high values: $1.0-2.0 \mathrm{~K}$ at heights of $200-400 \mathrm{hPa}$ and $0.5-1.0 \mathrm{~K}$ at heights of $500-900 \mathrm{hPa}$, before $0000 \mathrm{UTC}$ 21 September. Beyond that, the upper anomaly kept growing and developed into a distinct warm core. The warm anomaly reached $6.6 \mathrm{~K}$ at 0600 UTC 22 September. From this time until 1200 UTC 23 September, the airsea fluxes (sensible heat flux and latent heat flux) increased quickly from 262 to $903 \mathrm{~W} \mathrm{~m}^{-2}$, resulting in rapid TC intensification, as the MWS (MSLP) increased (decreased) from 27.1 (970 hPa) to $46.1 \mathrm{~m} \mathrm{~s}^{-1}$ (940 hPa). Meanwhile, the warm core developed rapidly, with the maximum warm anomaly reaching $9.4 \mathrm{~K}$ at heights of 200-400 hPa.

In the WRF Model, the air-sea fluxes also adopted the COR algorithm, although with an exchange coefficient of momentum flux modified by Davis et al. (2008). It should be noted that the effect of sea spray was not taken into account in the WRF Model.

The air-sea momentum, sensible heat flux, and latent heat flux based on observation and the model are shown in Fig. 13. In general, the WRF time series roughly agreed with the observation-based data, indicative of the model's relatively good performance when simulating TC track and intensity. The peak momentum fluxes in both the model and observation data occurred at nearly the same time, although the model results were weaker than the observation-based estimations. The peak momentum flux from the WRF was $4.37 \mathrm{~N} \mathrm{~m}^{-2}$, while the corresponding value using the COR algorithm was $5.37 \mathrm{~N} \mathrm{~m}^{-2}$. The lower momentum flux in the numerical model restricted the 

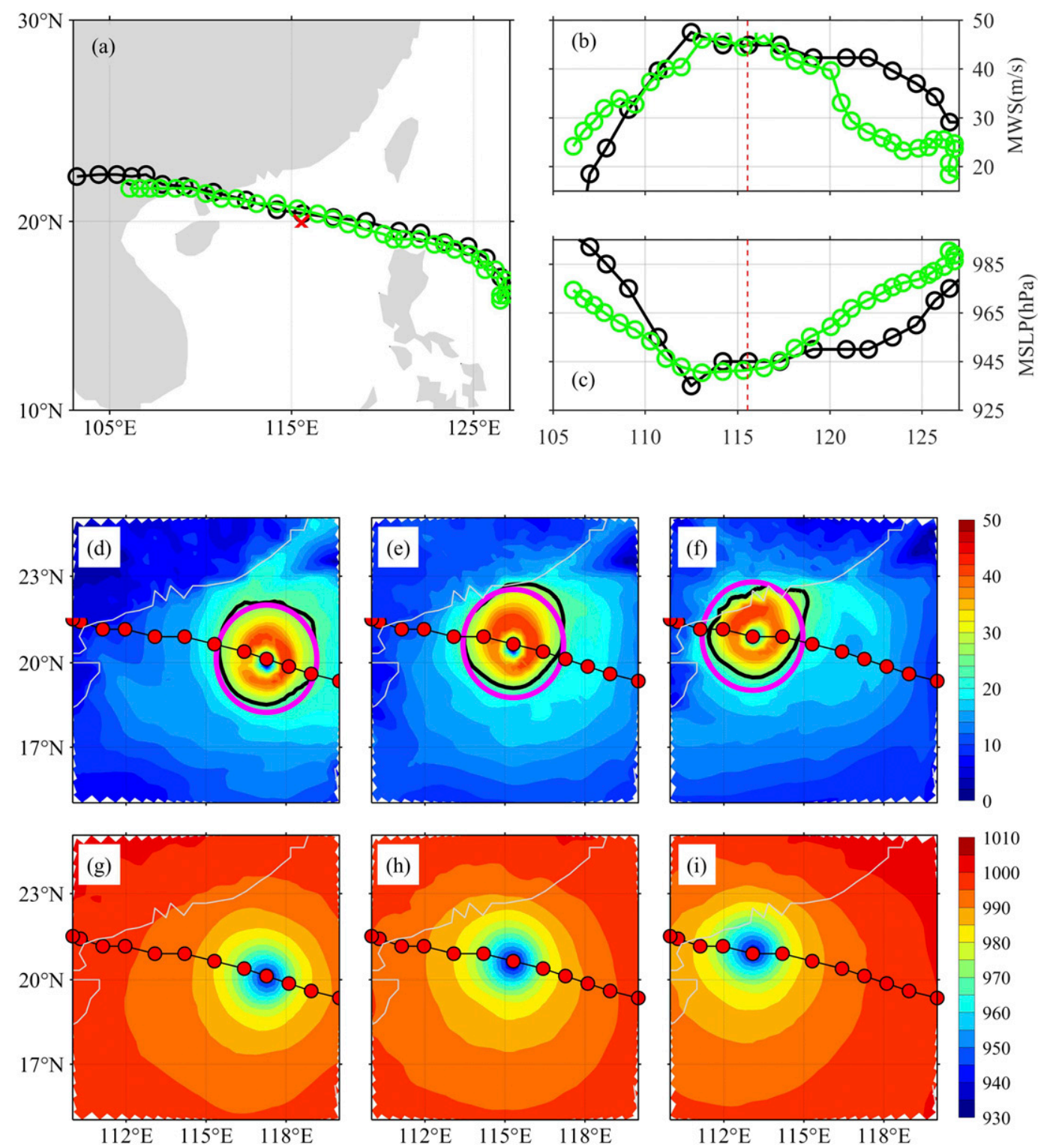

FIG. 9. Comparison of simulation results and JMA best track: (a) TC track, (b) 10-m MWS ( $\mathrm{m} \mathrm{s}^{-1}$ ), and (c) MSLP $(\mathrm{hPa})$. Green and black lines denote the simulation and best track data, respectively; the red $\mathrm{X}$ and dashed lines denote the buoy location and longitude, respectively; and the simulated 10-m wind speed with simulated track and radius of 50-kt wind overlaid at (d) 0000 UTC, (e) 0600 UTC, and (f) 1200 UTC 23 Sep (magenta and black circles denote radii from JMA and WRF results); and (g)-(i) the corresponding SLP.

mechanical energy flow from typhoon to ocean, thus inhibiting the simulated typhoon decay.

For the sensible heat flux, two notable differences were evident. First, the WRF overestimated the sensible heat flux compared to the COR (also in comparison with the LP and COR-WAVE). Second, the WRF sensible heat flux was nearly the same as that from the COR-SPRAY algorithm at 0600 UTC 23 September and comparable to the COR-SPRAY values during the entire TC period. Recalling that the WRF does not currently include the sea spray effect, there is a significant risk that it will generate unrealistically high sensible heat flux values if the sea spray effect is incorporated into it. For the latent heat flux, the model results were also greater than the observed values, especially prior to TC arrival at the buoy. For instance, at 1200 UTC 22 September, the WRF-simulated latent heat flux was $200 \mathrm{~W} \mathrm{~m}^{-2}$ greater than the COR estimate, with the latter having a value of only $100 \mathrm{~W} \mathrm{~m}^{-2}$. In other words, the WRF produced triple the latent heat flux of the observation-based 

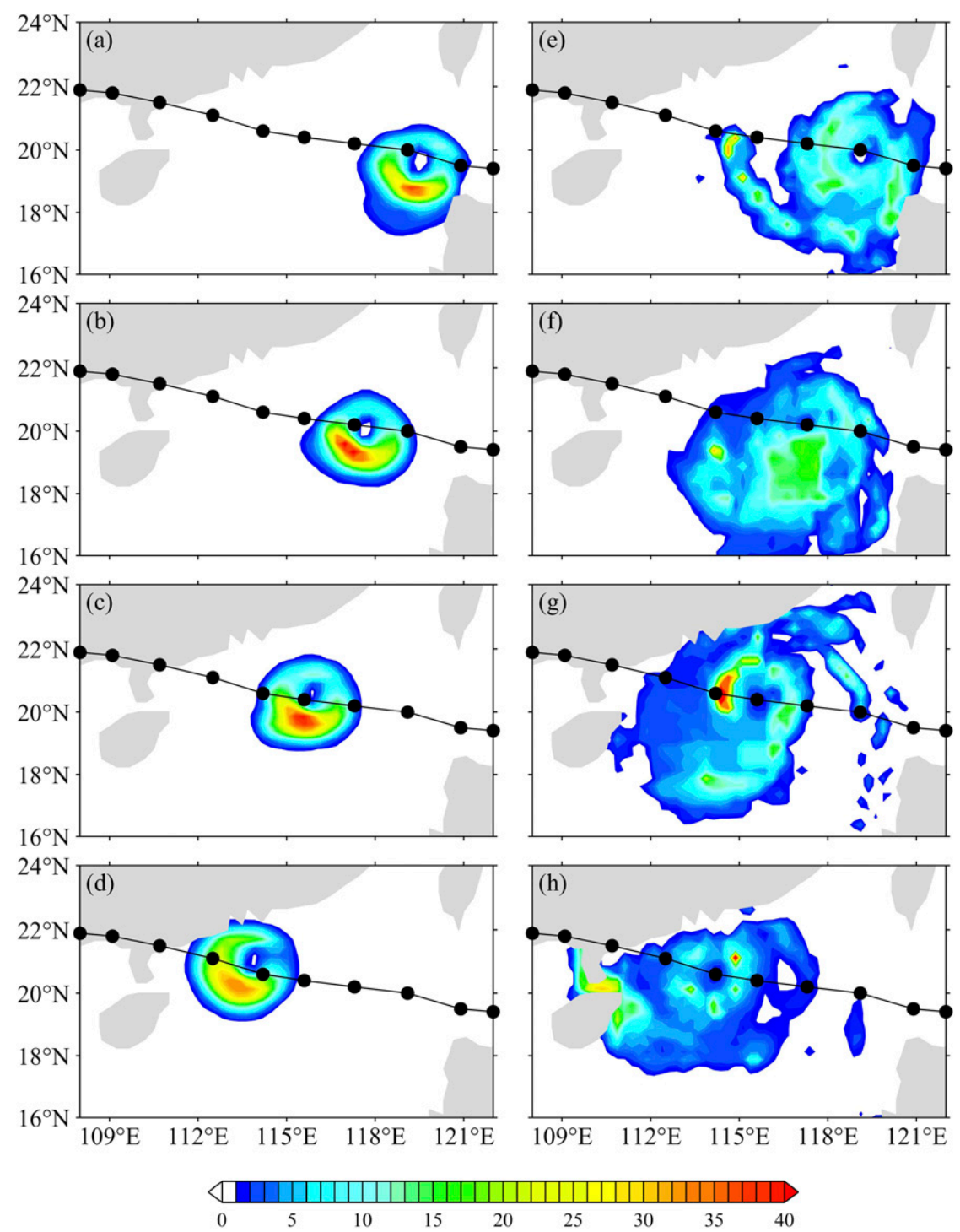

FIG. 10. Comparison of precipitation $\left(\mathrm{mm} \mathrm{h}^{-1}\right)$ : (left) WRF simulations and (right) satellitesensing observations with results at (a),(e) 1800 UTC 22 Sep, (b),(f) 0000 UTC 23 Sep, (c),(g) 0600 UTC 23 Sep, and (d),(h) 1200 UTC 23 Sep.

estimation. Overall, the results show that the model fluxes (both latent and sensible heat fluxes) were greater than those estimated by the four algorithms before Typhoon Hagupit reached the buoy.

Given the similarity between the bulk formulas of the WRF and COR for sensible and latent heat fluxes, the causes of the heat flux differences seem to be associated with the atmospheric and oceanic environments, as shown in Fig. 14. The comparisons of air pressure showcase the accuracy of the WRF simulation (Fig. 14a). The air pressure values were consistent between the two datasets, although the WRF outputs were slightly lower than observations prior to, and after, Hagupit passed by the buoy and higher than observation during the period of typhoon movement. For SSTs (Fig. 14b), the model simulation (forced by NCDC SST) did not accurately replicate the cooling signal, producing SSTs $1.5^{\circ} \mathrm{C}$ warmer than observation at the time of typhoon arrival at the buoy. In contrast, the air temperatures simulated by the WRF Model were close to observations (Fig. 14c), although some high-frequency signals existed in the in situ readings. The warmer SSTs in the numerical model supplied a more sensible heat flux to the typhoon, while in reality, SST cooling (or ocean dynamics) diminished the sensible heat flux (Fig. 13b) which inhibited the intensity of the typhoon. The surface humidity values generated by the numerical model were slightly greater than the observed 

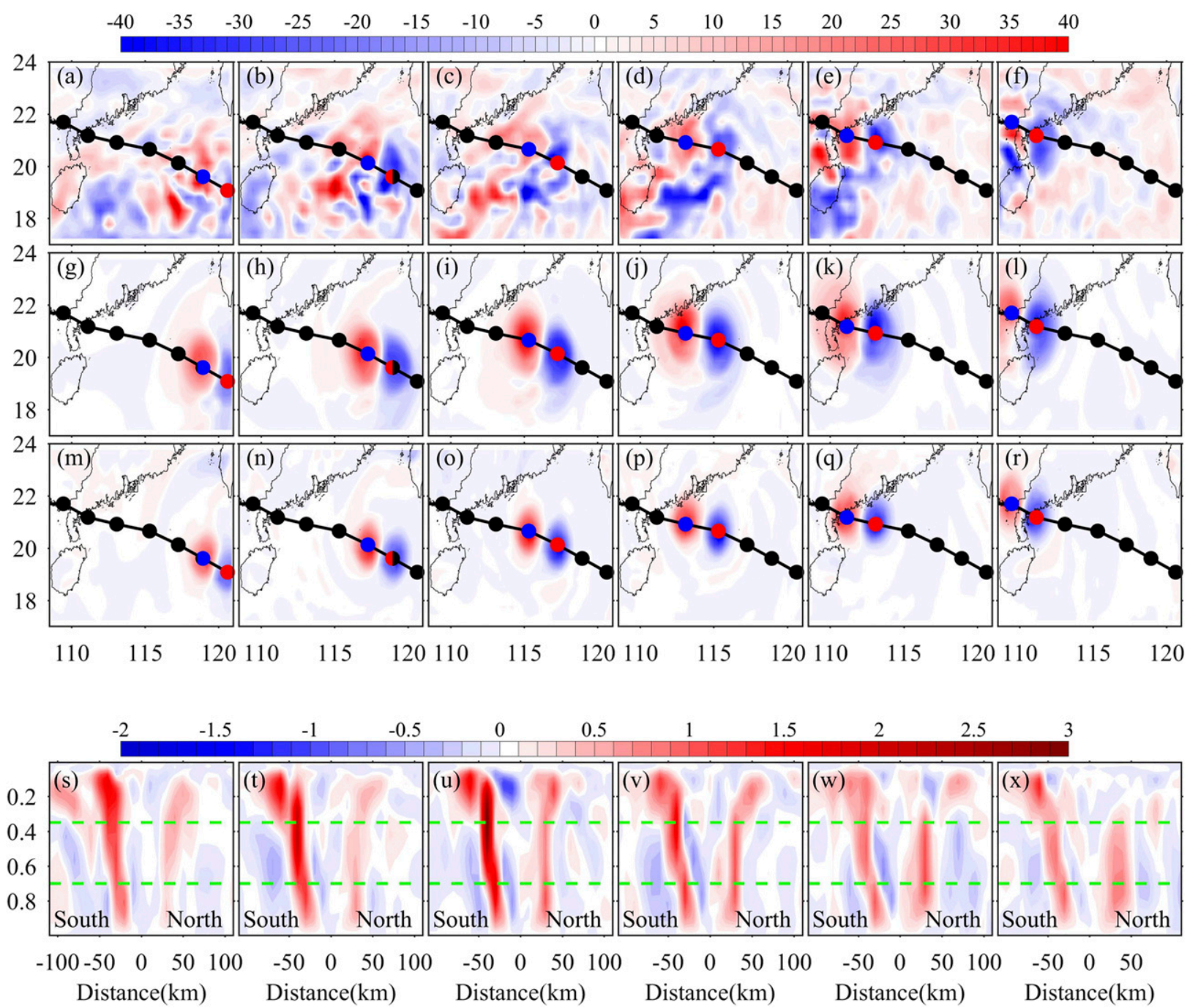

FIG. 11. PVT structures $\left(10^{-5} \mathrm{PVU} \mathrm{s}^{-1} ; 1 \mathrm{PVU}=10^{-6} \mathrm{~K} \mathrm{~kg}^{-1} \mathrm{~m}^{2} \mathrm{~s}^{-1}\right)$ of Typhoon Hagupit in (a)-(f) the top layer, (g)-(1) the middle layer, and $(\mathrm{m})-(\mathrm{r})$ the bottom layer, and $(\mathrm{s})-(\mathrm{x})$ the meridional-vertical profiles of VWS $\left(\mathrm{m} \mathrm{s}^{-1}\right)$. The red and blue dots denote the TC center at present and $3 \mathrm{~h}$ later, respectively.

measurements (Fig. 14d), most likely implying more evaporation and resulting in more latent heat flux in the simulation (Fig. 13c). For the 10-m wind speed (Fig. 14e), the WRF Model produced significantly higher wind velocities than the observed measurements, emphasizing the role of the reduced exchange coefficient of momentum flux by Davis et al. (2008). This reduced drag coefficient has been incorporated into the WRF and brings about higher wind speeds (Fig. 14e) but lower momentum flux (Fig. 13a) in the model simulation versus observation.

The NCDC SST used in the WRF simulations in this study was mainly based on the infrared satellite product and merged ship and buoy observations. Although NCDC SST is widely used in TC simulation (Wang et al. 2018), the interpolating method could filter out the high-frequency variations and weakens the SST cooling. The overrepresented SST in WRF would supply warmer sea surface for TC development, and the sensible heat flux would be directly enhanced. For the air humidity, WRF was considerable larger than the buoy, which implied that the moisture flux was overestimated in the WRF simulation against the observations. The phenomenon is also related to the warmer SST, because warmer SST induces larger vertical moisture difference between air and ocean, and therefore higher latent heat flux (Cione et al. 2013).

In the present simulation, we restricted the errors of track, intensity, and radius of the TC, but the errors of airsea fluxes emerged. WRF used the COR scheme, however, the WRF simulation suggested a vastly higher enthalpy 


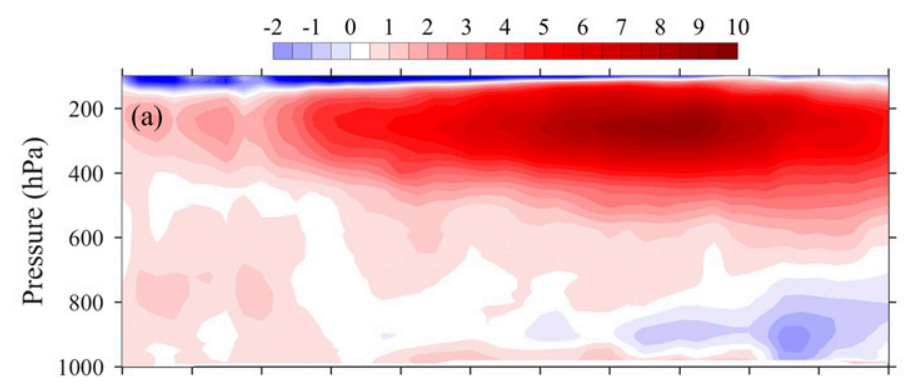

$\begin{array}{llllllllllllllllllll}12 Z 19 & 00 Z 20 & 12 Z 20 & 00 Z 21 & 12 Z 21 & 00 Z 22 & 12 Z 22 & 00 Z 23 & 12 Z 23 & 00 Z 24 & 12 Z 24 & 00 Z 25\end{array}$
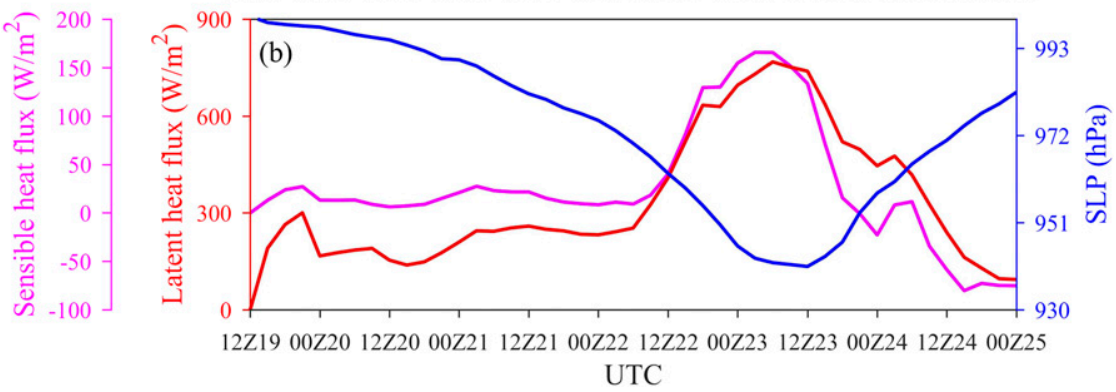

FIG. 12. Warm core development (blue and red shades; K), latent heat flux (red line; $\mathrm{W} \mathrm{m}^{-2}$ ), sensible heat flux (magenta line; $\mathrm{W} \mathrm{m}^{-2}$ ), and SLP (blue line; $\mathrm{hPa}$ ).

flux than the observation-based COR estimations. Meanwhile, the enthalpy flux in WRF simulation was close to the observation-based COR-SPRAY estimation, where COR-SPRAY took account of the sea spray effect. Assuming a large enthalpy flux was necessary in WRF to help the TC attained high intensity, some mechanics like the sea spray effect needed to be considered in the bulk formula. Similarly, if we further included the sea spray effect in the present WRF experiment, it is likely that the TC intensity would be oversimulated.

Here, we argue that the direct comparisons between model and buoy are not easy. The reasons are from at least three aspects. 1) The buoy sensors, especially wind sensors, are always destroyed by the typhoon. In this case, fortunately, the buoy worked well and recorded continuous data. 2) In numerical simulations, TC intensities are always underestimated. Here, the track, intensity, and radius are all relatively good. The sensitivity tests are probably case dependent, however, the relatively good simulation make the next-step buoy comparison feasible. 3) The bulk formulas leave a large uncertainty in estimating the turbulence fluxes (Figs. 13b,c). We show the uncertainty, as well as the best performance of state-ofthe-art atmospheric model, for pursuing first comparison between model and observational air-sea turbulent fluxes.

\section{Conclusions}

In this study, we used the WRF Model to simulate Typhoon Hagupit, which formed in the WNP and entered the SCS through the LS. Sensitivity tests were performed using an expanded set of CPSs and MPSs, consisting of a total of six CPSs and eight MPSs. The results emphasize the influences of CPSs and MPSs on TC track and intensity. For CPSs, the KF scheme demonstrated a distinct advantage over the other five schemes in hindcasting TC track and intensity.

The influences of CPSs to TC were characterized by the air-sea turbulent heat fluxes. For KF CPS, both latent heat flux and sensible heat flux were distributed higher along the TC tracks. The relatively higher turbulent heat fluxes around TC center helped the simulated TC gained more heat fluxes from ocean, and attained relatively reasonable TC intensity. For other CPS schemes, because the TC tracks were not well simulated, the TC center entered different places as compared with the best track, and the air-sea latent and sensible heat fluxes were dramatically changed because of different background atmospheric and oceanic environments. As a result, the TC intensities in other CPSs were commonly underestimated.

The performances of different CPSs were also displayed by the OLR at the top of atmosphere. KF CPS showed the most intensive OLR-related convection along the TC track. GD, whose TC track was mostly similar to $\mathrm{KF}$, exhibited weaker OLR-related convection than that in KF. For BMJ and G3, the OLR-related convection was slightly weaker than that in KF, however, because the track simulations were not good, the intensity simulations failed. For SAS and Tie, the OLR-related convection was comparatively very weak. 

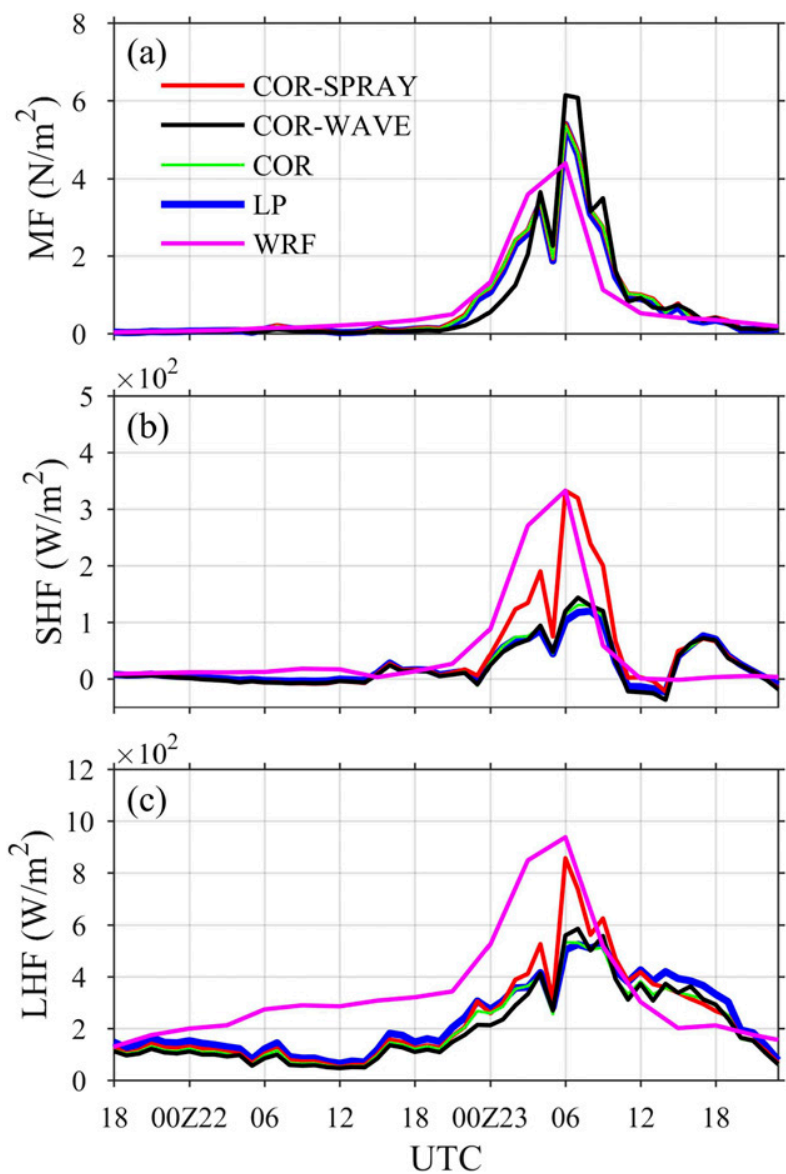

FIG. 13. Comparison of air-sea fluxes based on observation and model simulation: (a) momentum flux (MF), (b) sensible heat flux (SHF), and (c) latent heat flux (LHF).

Furthermore, the KF cumulus scheme, in combination with the Goddard microphysics scheme, was determined to be the optimal pairing for the reproduction of Typhoon Hagupit. The corresponding mean errors of track and intensity for this combination were $24.9 \mathrm{~km}, 11.3 \mathrm{~m} \mathrm{~s}^{-1}$ (MWS), and $6.0 \mathrm{hPa}$ (MSLP), respectively. The sensitivity tests revealed that WRF could attain relatively good track and intensity of the TC (Cangialosi 2018).

For the selected best simulation, the model results were also compared with satellite rainfall data for the purpose of a multipronged investigation. For Typhoon Hagupit, model precipitation magnitudes approached satellite estimates, which revealed the intensity of cumulus convection was primarily captured by the KF CPS. On the other hand, differences in the precipitation patterns were also discovered, with simulated rainfall located much closer to the typhoon eye than the more expansive observed precipitation shield. The results suggest the horizontal movement of cloud needs further improvement in the current atmospheric model.
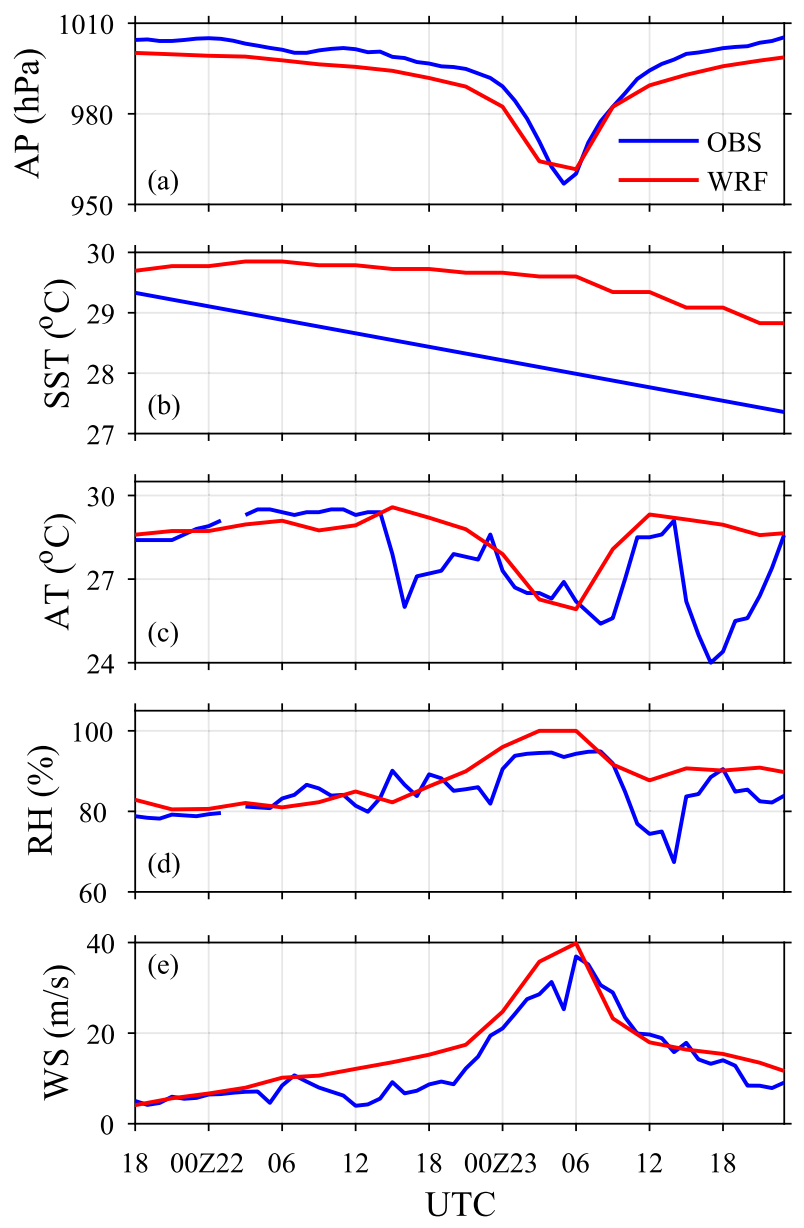

FIG. 14. Comparison of buoy-based atmospheric and oceanic parameters (blue lines) and model simulation (red lines): (a) surface air pressure (AP), (b) SST, (c) surface air temperature (AT), (d) surface relative humidity (RH), and (e) 10-m wind speed (WS).

One of the remarkable characteristics of Typhoon Hagupit was its asymmetric horizontal structure, which was evident in the rainfall and VWS data. Both precipitation and VWS were stronger in the left-front quadrant of the typhoon. We also studied the tilted vertical structure of Hagupit by investigating PV and VWS values. Extreme PVT values extended outward from the TC's center with increasing height, and VWSs were stronger and more tilted in the southern portion of the system than in the north.

More important, the model simulated air-sea fluxes were compared to those derived from a buoy in the SCS. When Hagupit passed by the buoy, the model errors for track and intensity were $18.4 \mathrm{~km}, 0.5 \mathrm{~m} \mathrm{~s}^{-1}$, and $3.2 \mathrm{hPa}$. This relatively accurate simulation made a direct comparison between model and buoy feasible. This comparison showed that the model's momentum flux values were slightly weaker than the observation-based bulk 
estimates. Meanwhile, the ocean in the numerical model released more heat flux via sensible and latent heat than was observed, even though the model's heat flux scheme was the same as one of the bulk formulas (COR). Since the model's sensible and latent heat fluxes were comparable to those of the sea spray-effect bulk formula (COR-SPRAY), this implies that the model potentially runs the risk of generating unrealistically high heat flux values if the sea spray effect were to be incorporated.

The differences in air-sea fluxes between the model and observation-based results were further explained by flux-related atmospheric and oceanic parameters, including air pressure, sea surface temperature, surface air temperature, and surface humidity. Higher sea surface temperature and slightly higher relative humidity are evident for WRF versus observation.

Comparisons between model and observation provide insight into the coupled typhoon-ocean system, although a single buoy observation is not nearly enough for the study of a typhoon. The errors on sea surface temperature and air humidity lead to vastly high turbulent heat fluxes. The drawback on sea surface temperature prompts a better sea surface temperature product as well as coupled atmosphere-ocean model. Investigating the physics of typhoon-ocean interactions requires additional observations, as well as further research.

Acknowledgments. This work was supported by the National Natural Science Foundation of China (41706034, 41830533, and 41376038), the National Science and Technology Major Project (2016ZX05057015), the National Programme on Global Change and Air-Sea Interaction (GASI-03-01-01-02, GASI-IPOVAI-01-05, GASIIPOVAI-04), and the NSFC-Shandong Joint Fund for Marine Science Research Centers (U1606405).

\section{REFERENCES}

Andreas, E. L, P. O. G. Persson, and J. E. Hare, 2008: A bulk turbulent air-sea flux algorithm for high-wind, spray conditions. J. Phys. Oceanogr., 38, 1581-1596, https://doi.org/ 10.1175/2007JPO3813.1.

Bao, J. W., 2016: Physical processes in tropical cyclone models. Advanced Numerical Modeling and Data Assimilation Techniques for Tropical Cyclone Prediction, U.C. Mohanty and S. G. Gopalakrishnan, Eds., Springer, 107-144, https://doi.org/ 10.5822/978-94-024-0896-6_4.

_ S. A. Michelson, and J. M. Wilczak, 2002: Sensitivity of numerical simulations to parameterizations of roughness for surface heat fluxes at high winds over the sea. Mon. Wea. Rev., 130, 1926-1932, https://doi.org/10.1175/1520-0493(2002)130<1926:SONSTP > 2.0.CO;2.

Cangialosi, J. P., 2018: National Hurricane Center forecast verification report: 2017 hurricane season. NOAA/NHC, 73 pp., https://www.nhc.noaa.gov/verification/pdfs/Verification_ 2017.pdf.
Chan, K. T. F., and J. C. L. Chan, 2016: Sensitivity of the simulation of tropical cyclone size to microphysics schemes. Adv. Atmos. Sci., 33, 1024-1035, https://doi.org/10.1007/s00376-016-5183-2.

Chen, L.-S., and Y.-H. Ding, 1979: An Introduction to the Western Pacific Typhoon (in Chinese). Science Press, $491 \mathrm{pp}$.

Choi, Y., K.-S. Yun, K.-J. Ha, K.-Y. Kim, S.-J. Yoon, and J. C. Chan, 2013: Effects of asymmetric SST distribution on straight-moving Typhoon Ewiniar (2006) and recurving Typhoon Maemi (2003). Mon. Wea. Rev., 141, 3950-3967, https://doi.org/10.1175/MWRD-12-00207.1.

Cione, J. J., 2015: The relative roles of the ocean and atmosphere as revealed by buoy air-sea observations in hurricanes. Mon. Wea. Rev., 143, 904-913, https://doi.org/10.1175/MWR-D-1300380.1 .

— E. A. Kalina, J. A. Zhang, and E. W. Uhlhorn, 2013: Observations of air-sea interaction and intensity change in hurricanes. Mon. Wea. Rev., 141, 2368-2382, https://doi.org/10.1175/ MWR-D-12-00070.1.

Davis, C., and Coauthors, 2008: Prediction of landfalling hurricanes with the Advanced Hurricane WRF Model. Mon. Wea. Rev., 136, 1990-2005, https://doi.org/10.1175/2007MWR2085.1.

Dudhia, J., 1989: Numerical study of convection observed during the Winter Monsoon Experiment using a mesoscale two-dimensional model. J. Atmos. Sci., 46, 3077-3107, https://doi.org/10.1175/15200469(1989)046<3077:NSOCOD>2.0.CO;2.

Emanuel, K. A., 1986: An air-sea interaction theory for tropical cyclones. Part I: Steady-state maintenance. J. Atmos. Sci., $\mathbf{4 3}$ 585-605, https://doi.org/10.1175/1520-0469(1986)043<0585: AASITF $>2.0 . \mathrm{CO} ; 2$.

- 1995: Sensitivity of tropical cyclones to surface exchange coefficients and a revised steady-state model incorporating eye dynamics. J. Atmos. Sci., 52, 3969-3976, https://doi.org/ 10.1175/1520-0469(1995)052<3969:SOTCTS $>2.0$.CO;2.

_ 1997: Some aspects of hurricane inner-core dynamics and energetics. J. Atmos. Sci., 54, 1014-1026, https://doi.org/10.1175/ 1520-0469(1997)054<1014:SAOHIC >2.0.CO;2.

— C. DesAutels, C. Holloway, and R. Korty, 2004: Environmental control of tropical cyclone intensity. J. Atmos. Sci., 61 , 843-858, https://doi.org/10.1175/1520-0469(2004)061<0843: ECOTCI $>2.0 . \mathrm{CO} ; 2$.

Fairall, C. W., E. F. Bradley, J. E. Hare, A. A. Grachev, and J. B. Edson, 2003: Bulk parameterization of air-sea fluxes: Updates and verification for the COARE algorithm. J. Climate, 16, 571-591, https://doi.org/10.1175/1520-0442(2003)016<0571: BPOASF $>2.0 . \mathrm{CO} ; 2$.

Fogarty, E. A., J. B. Elsner, T. H. Jagger, K. B. Liu, and K. S. Louie, 2006: Variations in typhoon landfalls over China. Adv. Atmos. Sci., 23, 665-677, https://doi.org/10.1007/s00376-006-0665-2.

Galvin, J. F. P., 2014: The development, track and destruction of Typhoon Haiyan. Weather, 69, 307-309, https://doi.org/10.1002/ wea.2458.

Green, B. W., and F. Zhang, 2013: Impacts of air-sea flux parameterizations on the intensity and structure of tropical cyclones. Mon. Wea. Rev., 141, 2308-2324, https://doi.org/10.1175/MWRD-12-00274.1.

Grell, G. A., and D. Dévényi, 2002: A generalized approach to parameterizing convection combining ensemble and data assimilation techniques. Geophys. Res. Lett., 29, 1693, https:// doi.org/10.1029/2002GL015311.

He, H.-L., Q.-Y. Wu, D.-K. Chen, J. Sun, C.-J. Liang, W.-F. Jin, and Y. Xu, 2018: Effects of surface waves and sea spray on air-sea fluxes during the passage of Typhoon Hagupit. Acta Oceanol. Sin., 37, 1-7, https://doi.org/10.1007/s13131-018-1208-2. 
Honda, T., and Coauthors, 2018: Assimilating all-sky Himawari-8 satellite infrared radiances: A case of Typhoon Soudelor (2015). Mon. Wea. Rev., 146, 213-229, https://doi.org/10.1175/ MWR-D-16-0357.1.

Hong, S.-Y., and J.-O. J. Lim, 2006: The WRF single-moment 6-class microphysics scheme (WSM6). J. Korean Meteor. Soc., 42 (2), 129-151.

- J. Dudhia, and S.-H. Chen, 2004: A revised approach to ice microphysical processes for the bulk parameterization of clouds and precipitation. Mon. Wea. Rev., 132, 103-120, https://doi.org/ 10.1175/1520-0493(2004)132<0103:ARATIM>2.0.CO;2.

Huffman, G. J., and Coauthors, 2007: The TRMM Multisatellite Precipitation Analysis (TMPA): Quasi-global, multiyear, combined-sensor precipitation estimates at fine scales. J. Hydrometeor., 8, 38-55, https://doi.org/10.1175/JHM560.1.

Janjić, Z. I., 1994: The step-mountain eta coordinate model: Further developments of the convection, viscous sublayer, and turbulence closure schemes. Mon. Wea. Rev., 122, 927-945, https://doi.org/ 10.1175/1520-0493(1994)122<0927:TSMECM>2.0.CO;2.

Jiménez, P. A., J. Dudhia, J. F. González-Rouco, J. Navarro, J. P. Montávez, and E. García-Bustamante, 2012: A revised scheme for the WRF surface layer formulation. Mon. Wea. Rev., 140, 898-918, https://doi.org/10.1175/MWR-D-11-00056.1.

Kain, J. S., 2004: The Kain-Fritsch convective parameterization: An update. J. Appl. Meteor., 43, 170-181, https://doi.org/ 10.1175/1520-0450(2004)043<0170:TKCPAU>2.0.CO;2.

Kessler, E., 1969: On the Distribution and Continuity of Water Substance in Atmospheric Circulations. Meteor. Monogr., Vol. 10, Amer. Meteor. Soc., 84 pp.

Kunii, M., 2015: Assimilation of tropical cyclone track and wind radius data with an Ensemble Kalman filter. Wea. Forecasting, 30, 1050-1063, https://doi.org/10.1175/WAF-D-14-00088.1.

Large, W., and S. Pond, 1981: Open ocean momentum flux measurements in moderate to strong winds. J. Phys. Oceanogr., 11, 324-336, https://doi.org/10.1175/1520-0485(1981) $011<0324$ :OOMFMI $>2.0 . \mathrm{CO} ; 2$.

_ and - 1982: Sensible and latent heat flux measurements over the ocean. J. Phys. Oceanogr., 12, 464-482, https://doi.org/ 10.1175/1520-0485(1982)012<0464:SALHFM >2.0.CO;2.

Li, F. N., J. B. Song, H. L. He, S. Li, X. Li, and S. D. Guan, 2016: Assessment of surface drag coefficient parameterizations based on observations and simulations using the Weather Research and Forecasting model. Atmos. Oceanic Sci. Lett., 9, 327-336, https://doi.org/10.1080/16742834.2016.1196105.

,$- \ldots$, and X. Li, 2018: A preliminary evaluation of the necessity of using a cumulus parameterization scheme in high-resolution simulations of Typhoon Haiyan (2013). Nat. Hazards, 92, 647-671, https://doi.org/10.1007/s11069-018-3218-y.

Lin, Y.-L., R. D. Farley, and H. D. Orville, 1983: Bulk parameterization of the snow field in a cloud model. J. Climate Appl. Meteor., 22, 1065-1092, https://doi.org/10.1175/1520-0450(1983) 022<1065:BPOTSF $>2.0$. CO; 2

Lin, K.-J., S.-C. Yang, and S. S. Chen, 2018: Reducing TC position uncertainty in an ensemble data assimilation and prediction system: A case study of Typhoon Fanapi (2010). Wea. Forecasting, 33, 561-582, https://doi.org/10.1175/WAF-D-17-0152.1.

Mlawer, E. J., S. J. Taubman, P. D. Brown, M. J. Iacono, and S. A. Clough, 1997: Radiative transfer for inhomogeneous atmospheres: RRTM, a validated correlated-k model for the longwave. J. Geophys. Res., 102, 16 663-16 682, https://doi.org/10.1029/97JD00237.

NCEP, 2000: NCEP FNL operational model global tropospheric analyses, continuing from July 1999. Research Data Archive at the National Center for Atmospheric Research, Computational and Information Systems Laboratory, Boulder, CO, accessed 19 December 2014, https://doi.org/10.5065/D6M043C6.

Owens, R. G., and T. D. Hewson, 2018: ECMWF forecast user guide. ECMWF, https://confluence.ecmwf.int/display/FUG/ Forecast+User+Guide, https://doi.org/10.21957/m1cs7h.

Pan, H. L., and W.-S. Wu, 1995: Implementing a mass flux convection parameterization package for the NMC medium-range forecast model. NMC Office Note 409, $40 \mathrm{pp}$.

Reynolds, R. W., T. M. Smith, C. Liu, D. B. Chelton, K. S. Casey, and M. G. Schlax, 2007: Daily high-resolution-blended analyses for sea surface temperature. J. Climate, 20, 5473-5496, https://doi.org/10.1175/2007JCLI1824.1.

Rogers, E., T. Black, B. Ferrier, Y. Lin, D. Parrish, and G. DiMego, 2001: Changes to the NCEP Meso Eta Analysis and Forecast System: Increase in resolution, new cloud microphysics, modified precipitation assimilation, modified 3DVAR analysis. NWS Tech. Procedures Bull. 488, NOAA/NWS, https:// www.emc.ncep.noaa.gov/mmb/mmbpll/mesoimpl/eta12tpb/.

Skamarock, W. C., and Coauthors, 2008: A description of the Advanced Research WRF version 3. NCAR Tech. Note NCAR/ TN-475+STR, 113 pp., https://doi.org/10.5065/D68S4MVH.

Stensrud, D. J., 2009: Parameterization Schemes: Keys to Understanding Numerical Weather Prediction Models. Cambridge University Press, $480 \mathrm{pp}$.

Tao, W.-K., J. J. Shi, S. S. Chen, S. Lang, P.-L. Lin, S.-Y. Hong, C. Peters-Lidard, and A. Hou, 2011: The impact of microphysical schemes on hurricane intensity and track. Asia-Pac. J. Atmos. Sci., 47, 1-16, https://doi.org/10.1007/s13143-011-1001-z.

Taylor, P. K., and M. J. Yelland, 2001: The dependence of sea surface roughness on the height and steepness of the waves. J. Phys. Oceanogr., 31, 572-590, https://doi.org/10.1175/15200485(2001)031<0572:TDOSSR $>2.0$. CO;2.

Thompson, G., P. R. Field, R. M. Rasmussen, and W. D. Hall, 2008: Explicit forecasts of winter precipitation using an improved bulk microphysics scheme. Part II: Implementation of a new snow parameterization. Mon. Wea. Rev., 136, 5095-5115, https://doi.org/10.1175/2008MWR2387.1.

Tiedtke, M., 1989: A comprehensive mass flux scheme for cumulus parameterization in large-scale models. Mon. Wea. Rev., 117, 1779-1800, https://doi.org/10.1175/1520-0493(1989)117<1779: ACMFSF $>2.0 . \mathrm{CO} ; 2$

Wang, X. D., X. Wang, and P. C. Chu, 2018: Air-sea interactions during the rapid intensification of Typhoon Fengshen (2008). Deep-Sea Res. I, 140, 63-77, https://doi.org/10.1016/j.dsr.2018.08.009.

Wu, C.-C., and K. A. Emanuel, 1993: Interaction of a baroclinic vortex with background shear: Application to hurricane movement. J. Atmos. Sci., 50, 62-76, https://doi.org/ 10.1175/1520-0469(1993)050<0062:IOABVW >2.0.CO;2.

_ G.-Y. Lien, J.-H. Chen, and F. Zhang, 2010: Assimilation of tropical cyclone track and structure based on the ensemble Kalman filter (EnKF). J. Atmos. Sci., 67, 3806-3822, https:// doi.org/10.1175/2010JAS3444.1.

Wu, L., and B. Wang, 2000: A potential vorticity tendency diagnostic approach for tropical cyclone motion. Mon. Wea. Rev., 128, 1899-1911, https://doi.org/10.1175/1520-0493(2000) 128<1899:APVTDA > 2.0.CO;2.

Xu, Y., H.-L. He, J.-B. Song, Y.-J. Hou, and F.-N. Li, 2017: Observations and modeling of typhoon waves in the South China Sea. J. Phys. Oceanogr., 47, 1307-1324, https://doi.org/10.1175/JPO-D-16-0174.1.

Yun, K.-S., J. C. Chan, and K.-J. Ha, 2012: Effects of SST magnitude and gradient on typhoon tracks around East Asia: A case study for Typhoon Maemi (2003). Atmos. Res., 109-110, 36-51, https:// doi.org/10.1016/j.atmosres.2012.02.012. 